\title{
Alarma por la resistencia a antimicrobianos: situación actual y desafíos
}

\author{
Teresa Camou*, Pablo Zunino†, María Hortal๋
}

\section{Resumen}

La creciente resistencia a los antimicrobianos (RAM) es un problema apremiante que de no combatirse a tiempo puede comprometer la salud de las generaciones futuras, con un retorno a la era preantibiótica. Frente a esa amenaza, los organismos sanitarios internacionales convocaron a todos los países para coordinar renovadas estrategias de lucha contra la RAM, promoviendo el enfoque de "una salud" con la participación de diferentes actores e instituciones. Este manuscrito proporciona información actualizada, explicando que la RAM no es más un dilema médico sino un fenómeno complejo que además afecta la producción agroveterinaria, el desarrollo y la economía de los países. La exposición a antibióticos contribuye a la selección de mutantes resistentes y favorece la transferencia horizontal de elementos genéticos móviles como plásmidos, integrones y tranposones que portan varios genes de resistencia contra distintas familias de antibióticos. Las antibioticoterapias, aun en situaciones justificadas, ejercen presiones selectivas que favorecen el predominio de mutantes bacterianas resistentes, por lo que es preciso evitar las infecciones, optimizando la higiene y el empleo de vacunas. También se ensayan terapias alternativas, por ejemplo basadas en bacteriófagos o probióticos. El Plan de Acción Mundial para controlar la RAM propuesto por la Organización Mundial de la Salud, la Organización Mundial de Salud Animal y la Organización de las Naciones Unidas para la Alimentación y el Desarrollo comprende cinco objetivos: mejorar la conciencia y el conocimiento sobre la resistencia antimicrobiana; reforzar la vigilancia y la investigación; reducir la incidencia de la infección; optimizar el uso de antimicrobianos, y asegurar una financiación duradera que asegure la persistencia de las acciones de control.

Palabras clave: FARMACORRESISTENCIA BACTERIANA

ANTIBACTERIANOS

SALUD GLOBAL

PLANES Y PROGRAMAS DE SALUD

Key words: $\quad$ BACTERIAL DRUG RESISTANCE

ANTI-BACTERIAL AGENTS

GLOBAL HEALTH

HEALTH PROGRAMS AND PLANS

\footnotetext{
* Investigadora, Programa de Desarrollo de Ciencias Básicas (PEDECIBA), Universidad de la República, Montevideo, Uruguay.

† Profesor Titular de Investigación del Departamento de Microbiología, Instituto de Investigaciones Biológicas Clemente Estable. Miembro de la Academia Nacional de Veterinaria.

$\ddagger$ Miembro $(\mathrm{H})$ Academia Nacional de Medicina: Prof/Investigadora, Programa de Desarrollo de Ciencias Básicas (PEDECIBA), Universidad de la República, Montevideo, Uruguay.

Los autores declaran no tener conflicto de intereses.

Correspondencia: María Hortal. Hidalgos 532/601, Montevideo, CP11300, Uruguay. Correo electrónico: marujahortal@gmail.com

Recibido: 31/7/17

Aprobado: 18/9/17
} 


\section{Introducción}

\subsection{Complejidad del problema}

La creciente resistencia a los antimicrobianos (RAM) es un problema candente, que de no combatirse a tiempo puede comprometer la salud de las generaciones futu$\operatorname{ras}^{(1)}$. Los microorganismos resistentes han aumentado dramática y exponencialmente en las últimas décadas como consecuencia del uso y abuso de antibióticos. La resistencia antimicrobiana ya no es solamente un dilema médico, sino una amenaza global que requiere, para su control, una acción coordinada de muchos y diferentes actores e instituciones.

Ese aumento exponencial de la RAM no solo compromete el futuro de la salud mundial, sino que afecta también la seguridad alimentaria, el desarrollo y la economía de los países ${ }^{(2)}$. Organismos sanitarios internacionales como la Organización Mundial de la Salud (OMS), la Organización Mundial de Salud Animal (OIE) y la Organización de las Naciones Unidas para la Alimentación y la Agricultura (FAO), entre otras, convocaron a todos los países con el fin de coordinar renovadas estrategias de lucha contra la RAM. Cada país, incluyendo Uruguay, se comprometió a elaborar un plan propio que contemple todos los aspectos de este complejo problema. Los planes nacionales han de ajustarse a lineamientos establecidos en un Plan de Acción Mundial, que con mancomunadas medidas persigue el objetivo de impedir una vuelta a la era preantibiótica ${ }^{(3)}$.

Todas las acciones apuntan a la consideración de "una salud" ("One health"), nuevo enfoque que reconoce las interacciones entre la salud humana, animal y ambiental especialmente en relación a la $\mathrm{RAM}^{(4)}$. La expansión mundial de la RAM es una pandemia silenciosa que para combatirla es necesario concientizar a todos los actores implicados, desde las máximas autoridades sanitarias hasta el último ciudadano. En consecuencia, este manuscrito tiene como propósito proporcionar información actualizada que permita comprender, al menos en términos generales, la responsabilidad de la que todos somos partícipes.

\subsection{Riesgos actuales}

En estos últimos años se ha comprobado un aumento cada vez más vertiginoso de las infecciones por bacterias multirresistentes y ya se han registrado situaciones límite en las que la infección es causada por una bacteria panresistente, es decir, resistente a todos los antibióticos disponibles ${ }^{(5)}$

Datos recientes del Centro para Control y Prevención de Enfermedades (CDC) confirman que en Estados Unidos la RAM es responsable de 2 millones de infecciones, con 23.000 muertes al año ${ }^{(6)}$. Además, otros es- tudios sugieren que el impacto de la resistencia en países de bajos o medianos ingresos podría ser mucho mayor (7). Un informe del Reino Unido estima que si no se controla la RAM, para el año 2050 las infecciones por bacterias resistentes causarán 10 millones de muertes anuales, sobrepasando la mortalidad por cáncer, además de afectar la economía mundial con cifras que alcanzarían los 100 mil millones de dólares al año ${ }^{(8)}$.

Es imprescindible administrar prudentemente los antibióticos ya que en las últimas dos décadas muy pocos han sido incorporados al arsenal terapéutico, especialmente para bacilos gramnegativos. La situación es tal que las enterobacterias productoras de carbapenemasas, resistentes a todos los beta-lactámicos y a otras familias de antibióticos, causan infecciones severas en pacientes inmunocomprometidos, prolongan las hospitalizaciones y aumentan las tasas de mortalidad entre $24 \%$ y $70 \%{ }^{(9)}$. En febrero de 2017, la OMS divulgó un listado de las 12 bacterias que deben ser consideradas prioritarias para la investigación y desarrollo de nuevos antibióticos, debido a las escasas opciones de tratamiento disponibles y su impacto en la salud pública ${ }^{(10)}$.

La globalización, con ilimitados intercambios de personas y mercaderías entre los países, favoreció la propagación mundial de bacterias resistentes contribuyendo también a la reemergencia de enfermedades olvidadas. Un ejemplo paradigmático fue la reciente diseminación de la enzima NDM (New Dehli metalocarbapenemasa), identificada por primera vez en Suecia en un paciente que había sido intervenido quirúrgicamente en la India ${ }^{(11)}$. Estudios retrospectivos indicaron que NDM se había diseminado en hospitales de la India y había contaminado también algunas fuentes de agua. En los años siguientes fue identificada en diversas especies bacterianas en pacientes hospitalizados de todo el mundo, incluso en Uruguay ${ }^{(12)}$.

La 71 ${ }^{\mathrm{a}}$ Asamblea General de Naciones Unidas realizó una declaración que señala a la RAM como una amenaza al cumplimiento de las metas de la Agenda 2030 sobre desarrollo sostenible. En la historia de las Naciones Unidas solo otros tres problemas de salud pública -sida, ébola y enfermedades no transmisibles- habían sido incluidos en su agenda, lo cual indica las consecuencias económicas que la RAM acarrea, fundamentalmente para los países en desarrollo ${ }^{(13)}$. Su efecto sobre la pobreza es particularmente preocupante: un estudio reciente del Banco Mundial indica que la RAM crea un escenario de alto impacto, en el que 24 millones de personas de países de bajos ingresos inexorablemente pasarían a la pobreza extrema en el año $2030^{(14)}$.

Indudablemente la resistencia ha dejado de ser únicamente un problema de la práctica clínica para convertirse en una amenaza global que afecta negativamente la economía y el desarrollo de los países. 


\subsection{Dinámica bacteriana}

Las bacterias, que fueron las primeras formas de vida en el planeta, poseen extraordinarios recursos de adaptación y supervivencia. Todo un mundo microbiano nos rodea, desde nuestra propia microbiota cutánea e intestinal, la que supera en número la totalidad de las células de nuestro organismo, hasta las más diversas poblaciones microbianas adaptadas a diferentes ecosistemas ${ }^{(15)}$. Además, las poblaciones bacterianas poseen un excepcional dinamismo: sus tiempos de multiplicación pueden ser muy breves, de apenas minutos, y son capaces de intercambiar material genético para optimizar su adaptación al ambiente que las rodea. La exposición a antibióticos no solo contribuye a la selección de mutantes resistentes, sino que además acelera las tasas de mutación ${ }^{(16)}$. Fundamentalmente favorece también la transferencia horizontal de elementos genéticos móviles como plásmidos, integrones y tranposones que portan genes de resistencia contra distintas familias de antibióticos y por tanto pueden ser seleccionados por el uso de cualquiera de ellos.

Las bacterias resistentes a antimicrobianos existen desde tiempos inmemoriales, pero se han ido adaptando y modulando durante el proceso evolutivo, como ya lo describió Darwin en su teoría sobre la evolución de las especies. Se ha detectado resistencia a antibióticos en bacterias presentes en cuevas subterráneas que han estado geológicamente aisladas de la superficie del planeta por 4 millones de años ${ }^{(17)}$.

La crisis actual es indudablemente resultado del comportamiento del hombre, que ha provocado un aumento exponencial en la exposición de las bacterias, patógenas y no patógenas, a los antibióticos. Un ejemplo del aumento vertiginoso de la RAM es la historia evolutiva reciente de las enzimas capaces de inactivar los antibióticos beta-lactámicos: el número de beta-lactamasas identificadas se ha multiplicado por diez desde 1990, sobrepasando actualmente las 1.000 enzimas diferentes ${ }^{(18)}$.

La voluminosa información obtenida a partir del análisis de genomas bacterianos completos, como resultado de la aplicación de nuevas tecnologías de secuenciación masiva, ha permitido establecer una base de datos de las secuencias de genes de resistencia. Esta base de datos, disponible para la comunidad científica, presenta un listado de más de 20.000 genes potenciales de resistencia, aunque los que realmente existen como determinantes funcionales son menos numerosos ${ }^{(19)}$.

Actualmente se investiga intensamente sobre el rol de la contaminación ambiental en la selección de resistencia y se ha encontrado que la presencia de bacterias resistentes es directamente proporcional al grado de in- tervención antropogénica en cada nicho ecológico. Aparentemente, no solo es el vertido de antibióticos al ambiente que podrían ejercer presión selectiva para la proliferación de cepas resistentes, sino también la contaminación con metales pesados ${ }^{(20)}$. Muchas bacterias del suelo poseen bombas de eflujo, desarrolladas para excluir moléculas nocivas, indistintamente metales o antibióticos. Por tanto, las bacterias que poseen ese mecanismo tendrían ventajas para sobrevivir en esos ambientes fuertemente contaminados. A su vez, las bacterias del suelo constituyen un reservorio de genes de resistencia que fácilmente se transmiten a otras especies, eventualmente patógenas para el hombre. Un ejemplo bien documentado es la transferencia de las betalactamasas tipo CTX-M desde una especie saprófita, Kluyvera ascorbata, a enterobacterias como Escherichia coli y Klebsiella pneumoniae, las que ulteriormente se diseminaron por centros hospitalarios de todo el mundo ${ }^{(21)}$.

\section{Trascendencia de la resistencia a los antimicrobianos}

\subsection{En medicina humana}

Hasta la cuarta década del siglo XX la mortalidad por enfermedades infecciosas predominaba en las estadísticas vitales. Enfermedades como la fiebre puerperal o la neumonía, entre otras, presentaban altísimas tasas de mortalidad. Las sulfamidas y en particular, poco después, la penicilina, representaron un progreso crucial que permitió combatir infecciones previamente leta $\operatorname{les}^{(22)}$. Sin embargo, Fleming ya había observado la aparición de mutantes resistentes como resultado de la exposición a penicilina en el laboratorio, razón por la cual realizó una advertencia en su discurso de recepción del premio Nobel. Ya en 1947 se describieron aislamientos clínicos de Staphylococcus aureus resistentes. No obstante, esas advertencias fueron ignoradas frente a la euforia por el éxito de los tratamientos. Además, como en 70 años se desarrollaron y produjeron en forma masiva más de 25 familias de antibióticos, se creó una falsa confianza en lo inagotable de la antibioticoterapia. Equivocadamente todavía hoy día predomina una fe casi ciega en los antibióticos tanto por parte de profesionales de la salud como de los pacientes y del público en general. Tampoco se reconoce a los antibióticos como los únicos fármacos con repercusión social, ya que su presión selectiva es inevitable a pesar de administrárselo a un único individuo ${ }^{(23)}$. Por tanto, para evitar las presiones selectivas es clave reducir las infecciones en la comunidad mediante estrictas medidas de higiene general que van desde el simple, pero efectivo, lavado de manos (figura 1) hasta complejas y exigentes pautas de habilitación sanitaria. En el ámbito hospitalario la re- 


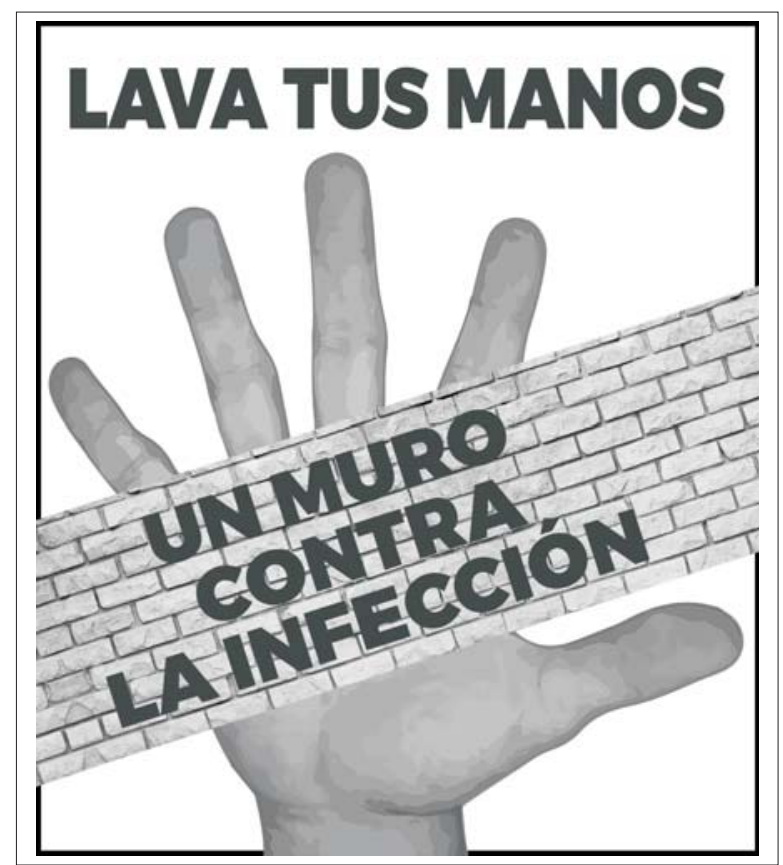

Figura 1. Importancia del lavado de manos.

percusión del empleo de antibióticos tiene mayor trascendencia: es responsabilidad de los comités de infección la implementación de enérgicas medidas de prevención y control, ya que son frecuentes los brotes intranosocomiales por bacterias multirresistentes de difícil y oneroso manejo terapéutico. También el empleo de las vacunas disponibles contribuirá a reducir las enfermedades infecciosas, que además de prevenir esas enfermedades en los vacunados, según la etiología, pueden reducir la diseminación de bacterias, protegiendo indirectamente a la población no vacunada ${ }^{(24)}$.

Las consecuencias de la RAM van más allá de fracasos terapéuticos: la RAM compromete el éxito de procedimientos complejos, como algunas cirugías, los trasplantes de órganos o la quimioterapia.

A escala mundial más del $50 \%$ de los antibióticos se prescriben, dispensan o venden de manera inapropia$\mathrm{da}^{(25)}$. En el primer nivel de atención la demanda por antibióticos es más frecuente e incontrolada ${ }^{(6)}$. A pesar de que los antibióticos no son efectivos en infecciones virales, frecuentemente se les prescribe. En ocasiones son los propios pacientes quienes los reclaman o recurren a la automedicación, con el agravante de administrarse dosis insuficientes o tratamientos incompletos, que son eficientes seleccionadores de mutantes resistentes en la comunidad $^{(26)}$. Son imprescindibles pautas consensuadas de manejo y selección de antibióticos para diferentes patologías y poblaciones comunitarias u hospitalizadas $^{(27)}$. En todas las instancias es necesaria una supervi- sión permanente y evaluación de la efectividad de lo pautado.

Otra forma de racionalizar el uso de antibióticos es el desarrollo de técnicas de diagnóstico etiológico y de susceptibilidad a antibióticos más precisas y rápidas, recursos fundamentales, tanto para la calidad de atención como para la vigilancia de la RAM.

Es imprescindible conocer la magnitud del consumo de antibióticos en humanos y animales y vigilar la diseminación de RAM en infecciones por bacterias patógenas y no patógenas. El nuevo paradigma es la vigilancia integrada del componente salud humana y el componente salud animal, bajo el lema "una salud"(3,4). Es necesario complementar la vigilancia con técnicas moleculares que permitan monitorizar los mecanismos de resistencia, los elementos genéticos móviles y la evolución de clones bacterianos multirresistentes.

El Ministerio de Salud Pública, preocupado por el aumento de la RAM, decretó la obligatoriedad de la receta médica para la venta de antibióticos en el año 2000; años después otros dos decretos intentaron prevenir tratamientos incompletos ${ }^{(28)}$. También, desde la década de 1980 se está procurando concientizar al personal sanitario y a la población respecto a los riesgos del uso y abuso de antibióticos. Casi tres décadas después aún no se ha logrado cambiar comportamientos que eviten el incremento exponencial de la RAM.

\subsection{En veterinaria}

Distintos factores hacen que el consumo de antibióticos asociados a la práctica veterinaria sea muy elevado. Se estima que la demanda mundial de proteínas en los 50 años que van entre 1980 y 2030 se multiplicará por 3,5. En consecuencia se requerirá lograr un balance entre el necesario incremento de la producción animal y vegetal y las estrategias para el logro de este objetivo, entre los que aparece como relevante el empleo de antimicrobianos. Por otra parte, las pautas culturales vinculadas a la relación entre seres humanos y mascotas han evolucionado hacia una intensificación del uso de estos fármacos. Hay actualmente, por parte de los propietarios, un mayor contacto con las mascotas y un incremento de los gastos asociados a su atención ${ }^{(29)}$.

Aunque las cifras acerca del empleo de antimicrobianos suelen ser controversiales, un estudio estima que a principios de siglo el $70 \%$ de los antibióticos producidos en Estados Unidos se empleaba en animales en ausencia de enfermedad ${ }^{(30)}$. Una inmensa cantidad de antibióticos ha sido utilizada a lo largo del tiempo en dosis subterapéuticas como suplementos promotores de crecimiento y para la profilaxis o tratamiento de infecciones en animales de producción masiva y también en el ámbito de la acuicultura. Por ejemplo, en Estados Unidos el 


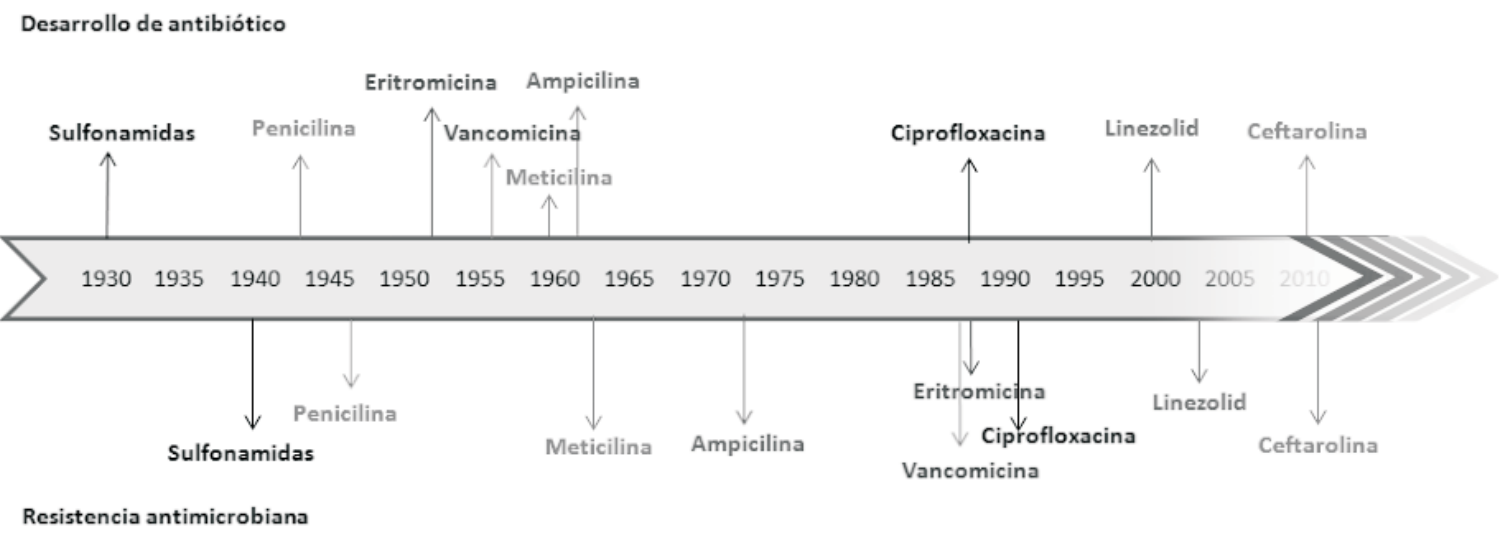

Figura 2. Desarrollo de antibióticos y tiempo transcurrido en aparición de resistencia.

volumen de antimicrobianos empleados como promotores de crecimiento aumentó 50 veces entre 1951 y 1978 (de 110 a 5.580 toneladas), mientras que en este mismo período el uso destinado al tratamiento de infecciones en humanos y animales se incrementó diez veces ${ }^{(31)}$. Se ejerció así una presión selectiva de bacterias resistentes que pueden diseminarse y afectar al ser humano directamente por contacto con los animales o a través de la cadena alimenticia e indirectamente por la contaminación del medio ambiente, por ejemplo por los efluentes de los establecimientos de producción animal ${ }^{(29,32)}$.

La situación de alarma generada por la aparición explosiva de resistencia bacteriana a antibióticos hizo que la Unión Europea prohibiera en forma generalizada en 2006 el uso de antimicrobianos con ese fin $^{(33)}$. Esta decisión fue el resultado de un camino que años atrás habían emprendido en forma individual algunos países europeos, fundamentalmente escandinavos ${ }^{(34)}$. En el ámbito local, en 2011 el gobierno uruguayo emitió un decreto presidencial $\left(\mathrm{N}^{\circ}\right.$ 98/011) que estableció la prohibición del uso de antibióticos en la alimentación para ovinos y bovinos. Esta preocupación se ha traducido también, en nuestro país, en otras resoluciones relativamente recientes que procuran regular y controlar el mal uso de los antibióticos, responsabilizando a los profesionales veterinarios por su correcta prescripción (DGSG, No 193A/015, 2015).

El uso imprudente de antibióticos en veterinaria también presenta una dimensión económica relevante. De acuerdo a proyecciones ya citadas del Banco Mundial, en un escenario de alto impacto de la resistencia a antimicrobianos, la caída de la producción pecuaria mundial podría oscilar entre $2,5 \%$ y $7,5 \%$ anual, y descender hasta $11 \%$ en los países de bajos ingresos ${ }^{(14)}$. Por otro lado, el mal uso de los antimicrobianos puede derivar en la generación de residuos en alimentos de origen animal.
Además de la relación con la emergencia de resistencias y los potenciales efectos deletéreos directos sobre los consumidores, los residuos implican un serio riesgo para el comercio internacional, ya que los mercados son cada vez más estrictos con respecto a estos requisitos ${ }^{(35)}$. Esto resulta especialmente relevante en países con una matriz fuertemente agroexportadora como Uruguay.

La mayoría de los antibióticos que se emplean en la práctica veterinaria comparten su uso con la clínica médica. En particular, algunos de los que se utilizan en salud animal son aquellos que se preservan para los casos más difíciles en la clínica humana. Colistina no era considerado un antibiótico de primera línea en salud humana por su efecto renal nocivo, pero hoy día es vital para el tratamiento de cepas multirresistentes de Acinetobacter, Pseudomonas aeruginosa, Klebsiella y Enterobac$\operatorname{ter}^{(36)}$. Recientemente fue descrita en China la resistencia plasmídica a colistina en aislamientos bacterianos de animales y humanos, e inmediatamente se comprobó su diseminación global ${ }^{(37)}$.

\section{Otros aspectos relevantes}

\subsection{Medidas alternativas o complementarias}

Durante las últimas décadas la investigación y el desarrollo de nuevos antibióticos por parte de la industria farmacéutica han estado librados a las leyes del mercado internacional. Es pertinente recordar que desde 1987 no se ha dispuesto de un antibiótico totalmente nuevo y que el tiempo transcurrido entre la introducción de un nuevo antibiótico y la aparición de cepas resistentes es cada vez más corto (figura 2). Por tanto, al no resultar una inversión rentable, la industria ha disminuido la investigación en este campo a favor de otros fármacos más redituables, por ejemplo los utilizados para enfermedades no transmisibles. 
Uno de los objetivos del Plan de Acción Mundial es fomentar la investigación y el desarrollo de nuevos antibióticos, movilizando recursos de los Estados, pero también explorar otras alternativas de profilaxis y tratamiento menos sujetas a la rápida aparición de resistencia.

Los péptidos antimicrobianos (AMP, por su sigla en inglés) son agentes naturales o sintéticos con actividad contra las membranas de los procariotas. Por ejemplo, las bacteriocinas son AMP producidas por prácticamente todas las especies bacterianas. Al ejercer presión selectiva solo sobre una especie bacteriana específica tendrían menor tendencia a desarrollar resistencia y podrían ser administrados en preparaciones múltiples o en combinación con antibióticos.

Otra estrategia que podría prolongar la vida útil de los antibióticos es la búsqueda de un vehículo que los traslade directamente al sitio de infección. Las nanopartículas podrían cumplir esa función, de manera de conseguir una concentración mayor del antibiótico que disminuya el riesgo de resistencia y evitar también la exposición al antibiótico de otras bacterias comensales.

Los bacteriófagos, virus que infectan la célula bacteriana y producen su lisis, pueden actuar de manera más rápida y eficiente que cualquier antibiótico. Tienen también la ventaja de ser específicos para una especie bacteriana, por lo que administrados como tratamiento mantendrían al resto de la microbiota intacta ${ }^{(38)}$.

La terapia fágica y los probióticos podrían sustituir, al menos en parte, a los antibióticos en la profilaxis de infecciones en humanos y animales. La microbiota intestinal de todos los mamíferos juega un rol preponderante para la salud: contiene entre $10^{10}$ y $10^{12}$ bacterias por gramo de contenido intestinal con más de 1.000 especies bacterianas diferentes, que modulan al sistema inmune, participan en la adquisición de nutrientes y excluyen a bacterias patógenas ${ }^{(39)}$. Los antibióticos afectan el equilibrio de esa microbiota e interfieren en sus funciones benéficas. Un ejemplo bien conocido son las diarreas por Clostridium difficile como consecuencia de tratamientos prolongados ${ }^{(40)}$. Las nuevas tecnologías, como la secuenciación masiva, permiten estudiar esa microbiota -inclusive de las especies no cultivables-y su relación con la salud, de manera de poder modularla con la introducción de bacterias exógenas benéficas conocidas como probióticos. Dos ejemplos exitosos son el uso de probióticos en la industria avícola ${ }^{(41)}$ y los trasplantes fecales a pacientes infectados por C. difficile ${ }^{(42)}$.

Otra potencial alternativa, aunque cada vez menos plausible por la creciente proliferación de bacterias resistentes a múltiples familias de antibióticos, es aprovechar la mayor velocidad de multiplicación de las bacterias susceptibles sobre las resistentes ${ }^{(43)}$. En el pasado, luego de prolongados períodos de ausencia de la presión selectiva por un determinado antibiótico, se había observado la recuperación de la susceptibilidad al fármaco, porque la población susceptible había prevalecido. Esta información, aunque utópica de momento, sería otro recurso de control de la RAM.

\subsection{Plan de Acción Mundial: principales estrategias}

Someramente se han revisado los principales problemas generados por la RAM en diversos ámbitos como medicina, veterinaria, seguridad alimentaria y medio ambiente.

El Plan de Acción Mundial propuesto por OMS, OIE y FAO establece cinco objetivos estratégicos: mejorar la conciencia y el conocimiento sobre la resistencia a los antimicrobianos; reforzar la vigilancia y la investigación; reducir la incidencia de la infección; optimizar el uso de antimicrobianos, y asegurar una financiación duradera ${ }^{(3)}$.

Los objetivos estratégicos planteados requieren acciones cooperativas claramente establecidas en el ámbito nacional e internacional. El éxito de su implementación se fundamenta en una mayor comprensión del fenómeno de la RAM, con la participación responsable y solidaria de todos los individuos, ya sean ciudadanos comunes, agentes sanitarios, investigadores, políticos o gobernantes.

\section{Summary}

The recent increase of antimicrobial resistance is a compelling problem that may compromise the health of future generations and result in us going back to the pre-antibiotic era, unless it is battled on time. In order to face this threat, global health organizations called countries to articulate new strategies to fight against antimicrobial resistance, by encouraging them to adopt a health centered approach that involves different actors and institutions. This report provides updated information, explaining the reasons why antimicrobial resistance is no longer a medical dilemma but rather a complex phenomenon that also affects agricultural and livestock production and the development and economy of countries. Antibiotic exposure contributes to the selection of resistant mutants and favors the horizontal transference of mobile genetic elements (MGE) such as plasmids, integrons and transposons, which carry several resistance genes against antibiotic families. Antibiotic therapy, still in justified situations, exerts selective pressure that favors the predominance of resistant bacteria mutants, and thus infections need to be avoided by optimizing hygiene conditions and relying on immunization. Also, alternative therapies are tried, as those based on bacteriophagists or probiotics. The Global Action Plan proposed by the WHO, the World Organization for Animal Health and the FAO to control antimicrobial resistance comprises five goals: to improve awareness 
and knowledge on antimicrobial resistance; to strengthen surveillance and research; to reduce the incidence of infection; to optimize the use of antimicrobial agents and to ensure a lasting funding that guarantees the continuation of control actions.

\section{Resumo}

A crescente resistência aos antimicrobianos (RAM) é um problema grave que, se não for combatido rapidamente, pode comprometer a saúde das próximas gerações, com um retorno à era pré-antibiótica. Considerando esta ameaça, os organismos sanitários internacionais convocaram todos os países para coordenar novas estratégias de luta contra a RAM, promovendo um enfoque de saúde, com a participação de diferentes atores e instituições. Este manuscrito proporciona informação atualizada, explicando que a RAM não é mais um dilema médico, mas um fenómeno complexo que afeta também a produção agro veterinária, o desenvolvimento e a economia dos países. A exposição a antibióticos contribui para a seleção de mutantes resistentes e favorece a transferência horizontal de elementos genéticos móviles como plasmídeos, integrons e tranposons que portam vários genes de resistência contra distintas famílias de antibióticos. As antibioticoterapias, mesmo em situações justificadas, exercem pressões seletivas que favorecem o predomínio de mutantes bacterianos resistentes, e, portanto é preciso evitar as infeções, otimizando a higiene e o uso de vacinas. Também foram feitos ensaios com terapias alternativas, por exemplo, baseadas em bacteriófagos ou probióticos. O Plano de Ação Mundial para controlar a RAM, proposto pela OMS, OIE e FAO compreende cinco objetivos: melhorar a consciência e o conhecimento sobre resistência antimicrobiana; reforçar a vigilância e a pesquisa; reduzir a incidência das infecções; otimizar o uso de antimicrobianos, e garantir um financiamento duradouro que assegure a persistência das ações de controle.

\section{Bibliografía}

1. World Health Organization. The evolving threat of antimicrobial resistance: options for action. Geneva: WHO, 2012. Disponible en: http://apps.who.int/iris/bitstream/10665/4481 2/1/9789241503181_eng.pdf. [Consulta: 8 junio 2017].

2. Organización Mundial de la Salud. Resistencia a los antibióticos. Ginebra: OMS, 2016. Disponible en: http://www.who.int/mediacentre/factsheets/antibiotic-resistance/es/. [Consulta: 8 junio 2017].

3. Organización Mundial de la Salud. Plan de acción mundial sobre resistencia a os antimicrobianos. Ginebra: OMS, 2015. Disponible en: http://www.who.int/antimicrobial-resistance/global-action-plan/es/. [Consulta: 8 junio 2017].

4. King LJ, Anderson LR, Blackmore CG, Blackwell MJ, Lautner EA, Marcus LC, et al. Executive summary of the
AVMA One Health Initiative Task Force report. J Am Vet Med Assoc 2008; 233(2):259-61.

5. Saleem AF, Ahmed I, Mir F, Ali SR, Zaidi AK. Pan-resistant Acinetobacter infection in neonates in Karachi, Pakistan. J Infect Dev Ctries 2009; 4(1):30-7.

6. Centers for Disease Control and Prevention. Antibiotic resistance threats in the United States, 2013. Atlanta, GA: CDC, 2014. Disponible en: https://www.cdc.gov/drugresistance/threat-report-2013/index.html. [Consulta: 8 junio 2017].

7. Laxminarayan R, Duse A, Wattal C, Zaidi AK, Wertheim HF, Sumpradit N, et al. Antibiotic resistance-the need for global solutions. Lancet Infect Dis 2013; 13(12):1057-98.

8. O'Neill J. Tackling drug-resistant infections globally: final report and recommendations. The review on antimicrobial resistance. London: AMR, 2016. Disponible en: https://amr-review.org/sites/default/files/160518_Final\%20paper_with\%20cover.pdf. [Consulta: 8 junio 2017].

9. Schwaber MJ, Klarfeld-Lidji S, Navon-Venezia S, Schwartz D, Leavitt A, Carmeli Y. Predictors of carbapenem-resistant Klebsiella pneumoniae acquisition among hospitalized adults and effect of acquisition on mortality. Antimicrob Agents Chemother 2008; 52(3):1028-33.

10. World Health Organization. Global priority list of antibiotic-resistant bacteria to guide research, discovery and development of new antibiotics. Geneva: WHO, 2017. Disponible en: http://www.who.int/medicines/publications/global-priority-list-antibiotic-resistant-bacteria/en/. [Consulta: 8 junio 2017].

11. Yong D, Toleman MA, Giske CG, Cho HS, Sundman K, Lee K, et al. Characterization of a new metallo-beta-lactamase gene, bla (NDM-1), and a novel erythromycin esterase gene carried on a unique genetic structure in Klebsiella pneumoniae sequence type 14 from India. Antimicrob Agents Chemother 2009; 53(12):5046-54.

12. Uruguay. Ministerio de Salud Pública. Departamento de Laboratorios. Detección de enterobacterias productoras de carbapenemasas (EPC). Monevideo: MSP, 2013. Disponible en: http://www.msp.gub.uy/publicaci\%C3\%B3n/detecci $\%$ C3\%B3n-de-enterobacterias-productoras-de-carbapenemasas-epc. [Consulta: 8 junio 2017].

13. General Assembly of United Nations. 71st session. Press release: high level meeting on antimicrobial resistance. New York: UN, 2016. Disponible en: http://www.un. org/pga/71/2016/09/21/press-release-hl-meeting-on-antimicrobial-resistance/. [Consulta: 8 junio 2017].

14. World Bank Group. Final Report: drug-resistant infections. A threat to our economic future. Washington, DC: World Bank, 2017. Disponible en: http://documents.worldbank.org/curated/en/32331149339 6993758/pdf/114679-REVISED-v2-Drug-Resistant-Infections-Final-Report.pdf. [Consulta: 8 junio 2017].

15. Baquero F, Nombela $\mathbf{C}$. The microbiome as a human organ. Clin Microbiol Infect 2012; 18(Suppl 4):2-4. 
16. Baquero F. From pieces to patterns: evolutionary engineering in bacterial pathogens. Nat Rev Microbiol 2004; 2(6):510-8.

17. Bhullar K, Waglechner N, Pawlowski A, Koteva K, Banks ED, Johnston MD, et al. Antibiotic resistance is prevalent in an isolated cave microbiome. PLos One 2012; 7(4):e34953.

18. Davies J, Davies D. Origins and evolution of antibiotic resistance. Microbiol Mol Biol Rev 2010; 74(3):417-33.

19. Liu B, Pop M. ARDB: Antibiotic Resistance Genes Database. Nucleic Acids Res 2009; 37:D443-7.

20. Baker-Austin C, Wright MS, Stepanauskas R, McArthur JV. Co-selection of antibiotic and metal resistance. Trends Microbiol 2006; 14(4):176-82.

21. Humeniuk C, Arlet G, Gautier V, Grimont P, Labia R, Philippon A. Beta-lactamases of Kluyvera ascorbata, probable progenitors of some plasmid-encoded CTX-M types. Antimicrob Agents Chemother 2002; 46(9):3045-9.

22. Hortal M, García Gabarrot G. Enfermedades infecciosas emergentes en Uruguay: memorias del siglo XX. An Fac Med Montev 2016; 3(2):7-23.

23. Levy SB. The antibiotic paradox: how the misuse of antibiotics destroys their curative powers. 2 ed. Cambridge, MA: Perseus Books Group, 2002.

24. García Gabarrot G, López Vega M, Pérez Giffoni G, Hernández $\mathrm{S}$, Cardinal $\mathrm{P}$, Félix $\mathrm{V}$, et al. Effect of pneumococcal conjugate vaccination in Uruguay, a middle-income country. PLoS One 2014; 9(11):e112337.

25. Macfarlane J, Holmes W, Macfarlane R, Britten $\mathbf{N}$. Influence of patients' expectations on antibiotic management of acute lower respiratory tract illness in general practice: questionnaire study. BMJ 1997; 315(7117):1211-4.

26. Grigoryan L, Haaijer-Ruskamp FM, Burgerhof JG, Mechtler R, Deschepper R, Tambic-Andrasevic A, et al. Self-medication with antimicrobial drugs in Europe. Emerg Infect Dis 2006; 12(3):452-9.

27. Rodríguez Baño J, Paño Pardo JR, Álvarez Rocha L, Asensio A, Calbo E, Cercenado E, et al. Programa de optimización de uso de antimicrobianos (PROA) en hospitales españoles: documento de consenso. Enferm Infecc Microbiol Clin 2012; 30(1):22e1-23.

28. Uruguay. Ministerio de salud Pública. Ordenanza 417/000: venta de antibióticos bajo receta profesional. Montevideo, 7 de julio 2000

29. Lloyd DH. Reservoirs of antimicrobial resistance in pet animals. Clin Infect Dis 2007; 45(Suppl 2):S148-52.

30. Mellon M, Benbrook C, Lutz Benbrook K. Hogging it: Estimates of antimicrobial abuse in livestock. Cambridge, MA: Union of Concerned Scientists, 2001. Disponible en: http://s3.documentcloud.org/documents/330307/jan-2001hogging-it.pdf. [Consulta: 8 junio 2017].

31. World Health Organization. Regional Office for Europe. Tackling antibiotic resistance from a food safety perspective in Europe. Copenhagen: WHO, 2011. Disponible en: http://apps.who.int/medicinedocs/documents/s18396en/s18396en.pdf. [Consulta: 8 junio 2017].

32. Liebana E, Carattoli A, Coque TM, Hasman H, Magiorakos AP, Mevius D, et al. Public health risks of enterobacterial isolates producing extended-spectrum beta-lactamases or AmpC beta-lactamases in food and food-producing animals: an EU perspective of epidemiology, analytical methods, risk factors, and control options. Clin Infect Dis 2013; 56(7):1030-7.

33. Castanon JI. History of the use of antibiotic as growth promoters in European poultry feeds. Poult Sci 2007; 86(11):2466-71.

34. Cogliani C, Goossens H, Greko C. Restricting antimicrobial use in food animals: lessons from Europe banning nonessential antibiotic uses in food animals is intended to reduce pools of resistance genes. Microbe 2011, 6(6):274-9.

35. Landers TF, Cohen B, Wittum TE, Larson EL. A review of antibiotic use in food animals: perspective, policy, and potential. Public Health Rep 2012; 127(1):4-22.

36. Pulcini C, Bush K, Craig WA, Frimodt-Møller N, Grayson ML, Mouton JW, et al; ESCMID Study Group for Antibiotic Policies. Forgotten antibiotics: an inventory in Europe, the United States, Canada, and Australia. Clin Infect Dis 2012; 54(2):268-74.

37. Liu Y-Y, Wang Y, Walsh TR, Yi LX, Zhang R, Spencer J, et al. Emergence of plasmid-mediated colistin resistance mechanism MCR-1 in animals and human beings in China: a microbiological and molecular biological study. Lancet Infect Dis 2016, 16(2):161-8.

38. Cisek AA, Dbrowska I, Gregorczyk KP, Wyzewski Z. Phage therapy in bacterial infections treatment: one hundred years after the discovery of bacteriophages. Curr Microbiol 2017; 74(2):277-283.

39. Whitman WB, Coleman DC, Wiebe WJ. Prokaryotes: the unseen majority. Proc Natl Acad Sci USA 1998; 95(12):6578-83.

40. Seija V, Balsamo A, Palacio R, Menéndez M, Batista N, Calata L, et al. Lecciones aprendidas en el estudio y diagnóstico de la infección por Clostridium difficile en el Hospital "Manuel Quintela". En: Academia Nacional de Medicina. Gran Premio Nacional de Medicina. Montevideo, Uruguay, 8 de diciembre de 2016.

41. Mead GC. Prospects for 'competitive exclusion' treatment to control salmonellas and other foodborne pathogens in poultry. Vet J 2000; 159(2):111-23.

42. Brandt LJ. Fecal transplantation for the treatment of Clostridium difficile infection. Gastroenterol Hepatol 2012; 8(3):191-4.

43. Torres Manrique C. La resistencia bacteriana a los antibióticos, siete décadas después del Fleming. Zaragoza: Colegio Oficial de Farmacéuticos, 2012. Disponible en: http://www.academiadefarmaciadearagon.es/docs/Documentos/Documento48.pdf. [Consulta: 2 julio 2017]. 